\title{
CRIANÇAS, GÊNERO E SEXUALIDADE: REALIDADE E FANTASIA POSSIBILITANDO PROBLEMATIZAÇÕES
}

\author{
Cláudia Maria Ribeiro \\ Universidade Federal de Lavras
}

\begin{abstract}
Resumo: Na dinâmica da intertextualidade, numa escrita rizomática, entreteci o roteiro de três filmes - A ostra e o vento, A teta e a lua e Inocente malícia - que trazem personagens crianças vivenciando, diferentemente, as descobertas da sexualidade e das relações de gênero. Teci esses roteiros com uma das ações do Projeto intitulado Tecendo Gênero e Diversidade Sexual nas Redes de Proteção, aprovado pela Secad/MEC em 2007, especialmente as ações do Subprojeto Direitos da Criança. Muitas crianças - personagens dessa gincana - possibilitaram a escrita de roteiros do cotidiano de processos educativos. Assim, o texto discute que o adulto, muitas vezes, exercita a violência de um olhar poderoso diante do desejo da criança - que pode driblar esse poder -, constituindo suas linhas de fuga. Mas, também, discute que o adulto pode, intencionalmente, possibilitar à criança encharcar-se das temáticas de sexualidade e gênero.

Palavras-chave: gênero; sexualidade; infância.
\end{abstract}

\section{Três filmes, três mergulhos nas sexualidades das crianças \\ O primeiro: a solidão das descobertas}

A ostra e o vento, um filme de Walter Lima Jr., ' acumula uma enchente de significados ao contar a história da menina Marcela, que vive em uma ilha na companhia apenas de

\section{Copyright (c) 2011 by Revista Estudos Feministas.}

${ }^{1}$ Ficha técnica: Walter Lima Jr. (diretor), Flávio R. Tambellini (produtor), Ravina Produções (produtora), Clóvis Bueno (direção de arte), Vera Hamburger (cenografia) e Rita Murtinho (figurinos). A história é a seguinte: "uma ilha, um farol, uns marujos, um louco shakespeariano, um faroleiro violento e sua filha adolescente querendo viver e amar, que enlouquece gradativamente de solidão, apaixonada pelo vento, que a possui como um amante invisível. Só isso. Quase nada acontece; o filme é sobre essa tragédia das coisas que não acontecem. A ilha é como se fosse um cinema ao avesso. Um grande cinema ao ar livre na noite, um cinema sem paredes" (Arnaldo JABOR, 1997). 
adultos: um pai repressor, o faroleiro José e um velho marinheiro, Daniel, trazido pelo mar. Companheiro, confidente, amigo e iniciador de Marcela na escrita. As águas do mar presença constante no filme - insistem no leva e traz dinâmico da vida. O diretor faz o mesmo movimento cinematográfico, nas idas e vindas do tempo, entretecendo passado, presente e futuro. Tudo que chega à ilha vem através do mar e retorna a ele; menos a menina Marcela, que é proibida pelo pai castrador de conhecer o continente, de relacionarse com outras pessoas.

À menina de $A$ ostra e o vento não era dada a oportunidade de descobrir no contato com outras crianças; descobre, sozinha, seu corpo e recorre à imaginação, fazendo do vento seu amante.

Os jogos de expressão da sexualidade, muitas vezes, são negados pelos adultos, bem como a informação sobre os temas de interesse das crianças. A curiosidade infantil, na temática da sexualidade, é grande; mas, às vezes, as crianças não têm oportunidade de falar sobre suas dúvidas, principalmente em relação a gravidez, nascimento, casamento, diferença entre os sexos, Aids, homossexualidade.

As brincadeiras infantis constituem-se numa maneira de a criança organizar o seu mundo, de apropriar-se das relações com outras crianças e adultos. A riqueza de sua sensibilidade e de sua expressão fazem-na inventar jogos que possibilitam descobertas de si mesma e do outro, tanto nas descobertas em relação à identidade sexual quanto nas descobertas da identidade de gênero.

O poder exercido pelo pai de $A$ ostra e o vento impunha verdades que negavam a sexualidade. A civilização ocidental, também dominada por uma tradição religiosa e pela imagem da infância ingênua, nega a sexualidade infantil. Muitas vezes, os desejos das crianças continuam representando um perigo em nossa sociedade e a importância das experiências de expressão da sexualidade na infância é subestimada. Ainda se nega a singularidade da criança, esquecendo-se de que a sexualidade é uma dimensão da existência que não tem idade; de que a criança elabora suas próprias teorias sobre a sexualidade de acordo com suas vivências, imersas em contextos culturais os mais diversos, manifestando sua sexualidade diferentemente do adulto. Por isso a sexualidade deve ser compreendida na temporalidade, no devir que caracteriza o ser humano. Muitas vezes, ainda hoje, a fala da sexualidade é ocultada ou tratada como forma de disciplina, tabu e submissão. Muitas vezes as crianças são impedidas de falar de seu corpo, de suas inquietações, de seus medos e alegrias na descoberta da sexualidade.

Muitas vezes a liberdade para a criança expressar suas curiosidades, sua abertura para a vida e para outras dimensões do ser humano, além da razão, é tolhida desde a tenra idade. Não só na infância, mas em qualquer idade, a educação como uma ação pela contradição e pela resistência navega em direção à reelaboração de padrões culturais que muitas vezes proíbem as expressões da sexualidade e as desconstruções dos estereótipos de gênero.

As ações do Projeto Educação Inclusiva: Tecendo Gênero e Diversidade Sexual nas Redes de Proteção remam em outra direção. E têm história!

\section{Escrevendo rizomaticamente}

Navegava pela história de Marcela, que descobria sozinha sua sexualidade. Mas minha escrita rizomática que entrelaçará, engalfinhará, entretecerá sexualidades e gênero, na realidade e na fantasia, exigirá que se contextualize porque é (im)possível ${ }^{2}$ remar em

\footnotetext{
${ }^{2}$ Jorge LAROSSA, 1999.
} 
outra direção. Mesmo que as águas sejam turbulentas. O roteiro, não de um filme, mas da vida real, começa em 2004 numa universidade pública brasileira.

A aprovação do Projeto Construindo Práticas a partir dos Compromissos com a Defesa dos Direitos Sexuais na Infância e Adolescência no Combate ao Abuso e Exploração Sexual envolveu a participação de 22 cidades do Sul de Minas Gerais, atendendo a editais do Programa de Apoio à Extensão Universitária voltado às Políticas Públicas - Proext, veiculado pelo Ministério da Educação - MEC, Secretaria de Educação Superior - Sesu, Departamento de Modernização e Programas da Educação Superior - Depem (2004, 2005 e 2006). Especialmente, a formação de professores/as que atuam no sistema educacional, na temática de sexualidade e gênero, desperta interesse e, ao mesmo tempo, medos, inseguranças, tabus, preconceitos. A experiência acumulada nesses anos, nas atividades de ensino, pesquisa e extensão do Departamento de Educação da Universidade Federal de Lavras (UFLA), revelou que não é suficiente indicar a inclusão do tema sexualidade no cotidiano das escolas, mas se torna premente atuar na construção de redes que possibilitem a concretização de políticas públicas. Assim, o referido Projeto foi elaborado, executado e, constantemente, avaliado, ciente da complexidade dos desafios. Portanto, articulou profissionais de escolas de educação infantil, fundamental e médio, agentes de saúde do Programa Saúde da Família (PSF), integrantes do Projeto Sentinela e integrantes de Conselhos Tutelares, com vistas a evidenciar as redes de proteção em cada cidade participante do projeto, estimulando a participação mais ativa no cotidiano dos sistemas de educação e saúde, na temática da sexualidade humana. Portanto, essa teia de interações que se constituiu foi alvo de pesquisas para sistematizar o processo de sua implementação.

Era o início de discussões sistemáticas com educadoras e educadores que atuam na educação infantil. Quanto desafio... Olhar para a sexualidade da criança, para a pedagogização do sexo das crianças, dispositivo específico de saber e poder que transformou a criança em objeto privilegiado da vontade de saber, constituindo a infância em objeto de intervenção higiênica e disciplinar.

O adulto ainda exercita a violência de um poderoso olhar diante do desejo erótico da criança - do qual não pode se apropriar -, mas tenta normatizar o que ela fala e sobre o que deve silenciar, o que mostrar e o que esconder. Dessa forma, a criança é apropriada sem enigma algum, objeto da vontade de dominação do adulto. O contrário exigiria renúncia da vontade de saber e poder; de toda vontade de domínio: um encontro com o enigma que se constitui a criança, o qual não pode ser apropriado nem decifrado. Constituise o segredo das crianças - um saber oculto que pode gerar poder sobre o adulto. E as crianças experimentam a vida driblando o poder do adulto.

As crianças são portadoras de uma verdade que devemos nos colocar à disposição para escutar, e isso requer nossa iniciativa: "Trata-se de devolver à infância a sua presença enigmática e de encontrar a medida da nossa responsabilidade pela resposta, ante a exigência que esse enigma leva consigo". ${ }^{3}$

Essa foi a grande pergunta que inundou a construção de novos cenários para outro projeto, também financiado pela Secad/MEC: Educação Inclusiva: Tecendo Gênero e Diversidade Sexual nas Redes de Proteção -, que objetivou qualificar técnica e politicamente professores/as e demais integrantes das redes de proteção com vistas a mobilizar a sociedade para participar na política de prevenção, atendimento, apoio e identificação das violências sexuais, no enfrentamento ao sexismo e à homofobia, organizando-se para ter instrumentos de controle social compartilhado e planejado nas 22 cidades do Sul de Minas, a fim de sensibilizar a todas e a todos para a gravidade das violências sexuais

${ }^{3}$ LAROSSA, 1999, p. 186 
contra crianças e adolescentes e continuar elaborando conjuntamente estratégias de ação para prevenir, sancionar e erradicar essas violências. Especificamente, o Projeto objetivou divulgar e garantir a efetivação dos direitos sexuais; registrar sob a forma de livro as experiências problematizadas decorrentes das atividades desenvolvidas durante três anos consecutivos de implementação do Projeto Construindo Práticas a partir dos Compromissos com a Defesa dos Direitos Sexuais na Infância e Adolescência no Combate ao Abuso e Exploração Sexual; realizar o Seminário Tecendo Sexualidade e Gênero nas Redes de Proteção em cada uma das 22 cidades, apresentando o livro publicado; oferecer exemplares do livro para subsidiar grupos de discussão; montar as Tendas Gênero e Sexualidade em cada uma das cidades paralelamente à apresentação dos seminários; realizar uma gincana cooperativa com as crianças, cujas professoras participaram do Subprojeto Direitos da Criança implementado nos três anos consecutivos; promover a participação de crianças, adolescentes e jovens na construção das ações para divulgação e utilização do telefone para denúncias e mobilização das comunidades; desenvolver uma campanha de comunicação sobre esse tema das violências sexuais, sexistas e homofóbicas através da imprensa local e regional (TV, rádios AM e FM, jornais); incrementar a página na internet ${ }^{4}$ para continuar divulgando os trabalhos realizados no âmbito desse Projeto; e articular uma rede de instituições visando à prevenção, punição e erradicação da violência sexual, sexista e homofóbica.

Esse foi o cenário para a realização da Gincana Cooperativa. Foram muitas pessoas envolvidas: docentes da universidade e das escolas municipais, discentes, familiares e crianças! Desafiando a criação de possibilidades de experimentação da vida. Ana Godoy ${ }^{5}$ incita a pensar: "Trata-se de se esquivar à banalização da vida, aos pensamentos e às práticas empobrecedoras e redutoras das possibilidades de experimentação da vida".

Para apresentar essa invenção e para dimensionar as possibilidades de experimentação, caracterizo a atividade. Primeiramente, as rotas cumpridas para participação: duas professoras ou professores, de cada cidade, que atuam na educação infantil com disponibilidade para planejar, executar e avaliar a realização da Gincana. Para tanto, deveriam participar de dois encontros de planejamento, com duração de oito horas cada; executar o projeto, ou seja, propor atividades para as crianças; participar com cinco crianças e respectivos/as responsáveis da Gincana Cooperativa, em data a ser prevista no mês de outubro; registrar o processo. Aos municípios caberia oferecer infraestrutura de transporte tanto para os dois encontros de planejamento em Lavras, MG, quanto para a participação da equipe (profissionais, crianças e responsáveis) no dia da Gincana Cooperativa, na cidade de Paraguaçu, MG.

Os encontros de planejamento foram também de estudos. Ao final das discussões, das negociações e das invenções cria-se o roteiro para a realização da Gincana Cooperativa: os Direitos das Crianças. Data: 25/10/2008. Local: Parque Municipal Coronel Olyntho Oliveira Leite, cidade de Paraguaçu, MG. Tarefas a serem apresentadas no dia da realização da Gincana: 1) propor atividades para desencadear a fala das crianças na temática dos seus direitos, registrá-la e apresentá-la; 2) problematizar as relações de gênero a partir da música "Cada um é como é" (CD Canção de Todas as Crianças, de Toquinho e Elifas Andreato). Elaborar e apresentar uma "esquete" em cinco minutos; 3) elaborar e apresentar um portfólio com as atividades desenvolvidas com as crianças a partir da música "De umbigo a umbiguinho" (CD Canção de Todas as Crianças, de Toquinho e Elifas Andreato); 4) apresentar os/as bonecos/as confeccionados/as pelas crianças e educadoras,

${ }^{4}$ Disponível em: <www.ded.ufla.br/direitosexuais >.

${ }^{5}$ Ana GODOY, 2008, p. 185. 
juntamente com os diários com o registro do passeio dos/as bonecos/as em cada casa; 5) ampliar a Tenda Gênero e Sexualidade; e 6) confeccionar um quadro para compor a colcha de retalhos (em saco de aniagem medindo $45 \mathrm{~cm} \times 45 \mathrm{~cm}$ ).

Rizomaticamente puxo o fio da história de Marcela, personagem do filme de $A$ ostra e o vento. Descobria sozinha sua sexualidade e os meandros das relações de gênero. Muito diferente das crianças participantes da gincana: 90 crianças com a idade de cinco anos das cidades de Paraguaçu, Nepomuceno, Cambuquira, Carmo da Cachoeira, Perdões, Três Pontas, Itumirim, Itutinga e Lavras, todas do estado de Minas Gerais. E mais: 5 familiares e 2 professoras de cada cidade. Especialmente da cidade de Paraguaçu: 50 crianças, 50 familiares, 10 professoras. Equipe da UFLA: total de 15 pessoas entre discentes e docentes. Total: 233 pessoas. Muita possibilidade de trocas. Muitos questionamentos: não é arriscado viajar com tantas crianças de cinco anos de idade? Como vocês vão organizar tudo? Criança pequena falando de sexualidade? Ana Godoyb incita a pensar em traições: "Devircriança, devir-animal, enfim, todos os devires implicam algum tipo de traição: traição à forma, traição à norma". As traições estavam planejadas!

Um dia em um parque municipal é uma grande invenção: "invenção de possibilidades de vida, de modo de existência: de invenção e experimentação de si. A invenção de si é movida por uma vontade que afirma - novamente: um pensamento ativo para uma vontade que afirma". ${ }^{7}$

A experimentação de si requer contatar outros. Como no filme A teta e a lua!

\section{O segundo filme: diferentes desejos e as relações de gênero}

Outro filme no qual mergulhei, $A$ teta e a $l u a,{ }^{8}$ possibilita problematizar a sexualidade infantil ao abordar os desejos diferentes de três homens: uma criança, um adolescente e um adulto, apaixonados por uma mulher - Estrelita.

Transformação, movimento, múltiplos desejos, gênero são os temas de A teta e a lua. Encontramos nas cenas iniciais o menino Tete escalando uma pirâmide humana, sendo incitado pelo pai a provar que é homem: "mostre que tem colhões". Pirâmide e escada indicam ascensão gradual: lugar onde o alto e o baixo, o céu e a terra, a fantasia e a realidade podem juntar-se. A escalada gera medo, temor, angústia, perdas, mas também alegrias, conquistas. Subidas e descidas, ritmo. O símbolo da escada, da pirâmide humana composta só de homens, contém uma significação erótica, sendo a ascensão do desejo. $E$ só os homens conseguem!

Tete perde e ganha em sua progressão para o saber, em sua ascensão para o conhecimento. Perdeu a sensação de flutuar no líquido amniótico, quentinho e acolhedor e perdeu o seio da mãe para o irmãozinho que nasce. O seio está ligado à proteção, à fertilidade e ao leite, símbolos da doçura e da segurança; pequenas almofadas de amor que o menino resolve buscar em outra mulher, encontrando-os em Estrelita, a dançarina. Ao seio associam-se imagens de intimidade, de oferenda, de dádiva e de refúgio; ao leite, as imagens de crescimento; o leite é um símbolo lunar, feminino por excelência.

O menino Tete, ao perder o seio da mãe para o seu irmãozinho que acabara de nascer, recebeu um impulso novo para a vida. O mundo da água, que operou em sua vida

${ }^{6}$ GODOY, 2008, p. 285.

7 GODOY, 2008, p. 285.

${ }^{8}$ Ficha técnica: Bigas Lunas (diretor), Andrés Vicente Gómes (produtor), Cecilia Moliné (roteiro), José Luis Alcaine (fotografia), Mathilda May, Gerard Darmon, Miguel Poveda, Biel Duran e Abel Folk (atores). A teta e a Iua conta a história de dois homens e um garoto apaixonados pela mesma mulher: Estrelita. Maurice, o marido, Miquel, um adolescente que sente eletricidade cada vez que a toca, e Tete, um garoto que está louco por sua teta, pois a teta de sua mãe foi roubada por seu irmão menor. 
desde o meio intrauterino ao ambiente exterior, era cúmplice de suas descobertas, pois, no desenrolar de A teta e a lua, esse elemento escorre por entre as cenas do filme.

Com o nascimento do irmão, Tete resolve procurar uma teta só para si; a cena desenrola-se numa fonte. A sacralização das fontes é universal, símbolo da maternidade. Tete e seu amigo conversam sobre tetas: "as mulheres estão cheias de leite e as guardam na teta"; "toda noite meu pai enche minha mãe de leite"; "ela diz: dê-me teu leite, enchame de teu leite". E o menino diz que isso era culpa do irmãozinho, que a esvaziava durante o dia, e o pai - que tinha muito leite - tinha que enchê-la à noite.

Para o pai de Tete, a preocupação com o filho era com a demonstração de sua masculinidade - com os seus colhões e os seus dentes. Dessa forma, a criança de $A$ teta e a lua sentia-se livre para expressar sua sexualidade, para buscar o seu desejo - a sua teta -, para fantasiar, para sonhar o seu sonho. O que importava para sua família era a sua masculinidade - os colhões de touro.

Às vezes as crianças têm interlocutores/as para dissipar as suas dúvidas; às vezes o controle se dá através da culpa e, às vezes, a criança esperneia e realiza seus desejos.

Esse medo de ser descoberto pelo adulto e a falta de parâmetros a respeito das fantasias, posturas e expressões de sua sexualidade não representavam problema para o menino de A teta e a lua. A constituição de sua identidade seguia seu curso-diferente das outras idades dos homens que se apaixonaram pela mesma mulher: três desejos diferentes. Por isso a lua é elemento fundamental no filme. Ela é o símbolo dos ritmos biológicos, por suas fases sucessivas e regulares.

As fantasias e os desejos de três homens - criança, adolescente e adulto - e uma mulher trazem, portanto, no transcorrer do filme, a diferença. A teta e a lua inicia-se com a dançarina saindo de uma caixa. A dançarina anuncia as diferentes linguagens, os diferentes desejos dos homens do filme. Ao dançar anunciava a libertação no êxtase.

No decorrer do filme, nos labirintos das significações, a água é um elemento presente nos encontros de Tete com seu avô - amigo e confidente - que aconteciam na praia, com o leva e traz das ondas do mar, presenciando as infindáveis conversas sobre as dúvidas do menino; no colchão de água de Estrelita; nas lágrimas guardadas em um vidrinho; na rã animalzinho de estimação de Tete - relacionada com a água e com as metamorfoses.

O desejo adolescente era o coito: "não consegue tirar a xoxota dela da cabeça?", dizia Tete referindo-se à calcinha que Miquel havia roubado da dançarina. O desejo adulto, que não tinha mais ereção, era viver suas fantasias com a dançarina e o desejo da criança era ter a sua teta: ele queria ver. Seguia-a por toda a parte e fantasiava suas tetas: "Ela me mostrou sua teta. Nunca pensei que havia teta mais bonita que a da minha mãe. Eu estava apaixonado!".

A criança de A teta e a lua buscava realizar suas fantasias. Não havia o limite do permitido/proibido - seu pai e sua mãe preocupavam-se com os seus dentes; o que havia era a competição com os seus rivais: o adolescente e o adulto. Isso não impedia o acesso a Estrelita: "quero sua teta e seu leite. Dê-me um pouco de seu leite por favor".

Viver essa experiência, com suas possibilidades de criança, fê-lo enfrentar os outros desafios da vida: escalar a pirâmide. No momento da empreitada aparece Estrelita e dáIhe de seu leite: "tinha as tetas mais doces do mundo!". Aparece a mãe e lhe dá, também, de seu leite: "era muito mais gostoso que o de Estrelita". E, com todas essas almofadas de amor, Tete consegue escalar a pirâmide: agora tinha colhões de touro!

Quanto aprendizado na vida dessa criança. A história de Tete, entrelaçada com a do adolescente e a do adulto, possibilita reafirmar que a sexualidade e as relações de gênero são construídas ao longo da vida: "As muitas formas de fazer-se mulher ou homem, as várias possibilidades de viver prazeres corporais são sempre sugeridas, anunciadas, 
providas socialmente [...] Elas são também, renovadamente, reguladas, condenadas ou negadas". 9

O roteiro do filme $A$ teta e a lua nos insere em determinada cultura. O menino expressava seus desejos e prazeres sem a interferência do adulto. O roteiro da Gincana Cooperativa foi outro: desencadear intencionalmente a fala da criança sobre gênero e sexualidade. A criança está constituindo sua identidade de gênero e sua identidade sexual, e, nesse movimento, muitos discursos são veiculados indicando o que falar e o que não falar, o que pode e o que não pode, o que mostrar e o que esconder. Para não perpetuar estereótipos, concepções machistas, sexistas, homofóbicas, desde a mais tenra idade, o adulto é desafiado a inventar propostas nas quais as crianças são instigadas a discutir as formas como a sexualidade e as relações de gênero têm sido normalizadas, normatizadas, infantilizadas.

Assim, a equipe responsável pela Gincana Cooperativa - inundada da questão advinda dos estudos de Jorge Larossa ${ }^{10} \mathrm{em}$ relação às crianças (qual a medida da nossa responsabilidade?) - inventou, primeiramente, um jeito de as crianças discutirem, em suas instituições de educação infantil, a temática da sexualidade e de gênero e inundarem o horto florestal com as suas produções: teatros, portfólios, maquetes, colagens, bonecos e boneca, dentre outros.

Algumas cenas:

A viagem: crianças, familiares, educadoras transportadas em kombis, vans, microônibus. Lanches, matulas, merendas. Expectativa do que encontrariam em Paraguaçu.

A abertura da Gincana: danças circulares com todos/as os/as 233 participantes. E mais, participando da grande roda: os bonecos e as bonecas confeccionados/as pelas crianças e educadoras.

Logo após as crianças e as educadoras foram divididas em grupos de 10 crianças, duas educadoras e dois discentes para percorrerem um circuito em vários espaços, previamente organizados: escorrega na pista de skate; jogo com bolas de vários tamanhos, na quadra de futebol de salão; casinha de bonecas em uma árvore; trilha dentro da mata com os pés descalços; tenda: duas barracas de praia ambientadas com os mais diversos brinquedos, tapetes de sensações, fantasias para brincadeira de faz-de-conta, livros para crianças na temática de gênero e sexualidade, bolas de isopor de vários tamanhos dependuradas com fios de nylon, bonecas grávidas, bancos coloridos, almofadas, bacias recobertas de pano colorido (com um buraco no meio contendo geleca), sementes, bolinhas de todos os tamanhos; espaço para os/as bonecos/as; espaço para os portfólios com os direitos da criança; espaço para as atividades feitas a partir da música "De umbigo a umbiguinho".

E as famílias das crianças? Que surpresa para elas! Se pensavam acompanhar as crianças no parque, outra situação aconteceu. Foram convidadas a participar de uma oficina temática sobre as violências sexuais.

E, no final do circuito, as crianças encontraram-se para apresentar as "esquetes" criadas para abordar as relações de gênero a partir da música "Cada um é como é". E as famílias também foram convidadas.

Com esse cenário, quanta possibilidade de descobertas, na dinâmica interativa. Essa foi a experiência do personagem do filme a seguir.

\footnotetext{
9 Guacira Lopes LOURO, 2007, p. 9

${ }^{10}$ LAROSSA, 1999.
} 


\section{O terceiro filme: as descobertas na dinâmica interativa}

O filme sueco Hin Helgu Vêl' - The Sacred Mound - referindo-se ao túmulo sagrado dos vikings, existente numa ilha, é cenário de muitas descobertas para o menino Gestur. A tradução do título para o português Inocente malícia reforça a imagem da infância inocente e reduz ao apelo sexual a fértil imaginação de um menino de sete anos, às voltas com os heróis dos jogos de videogames, os ciúmes da mãe e de uma moça de 20 anos, os embates com uma menina da mesma idade que ele e que geram muitas descobertas. No filme The Sacred Mound, três mulheres de diferentes idades possibilitam ao menino Gestur a vivência de diferentes sentimentos e emoções.

Ora meninos, ora meninas, são ensinantes e aprendentes. No filme The Sacred Mound o menino era muito estimulado pela televisão, pelos videogames e pelos heróis. Adorava e via frequentemente as histórias sobre os vikings; tinha chapéu, espada, colete... Quando precisa viajar para uma ilha, entra em contato com uma lenda local: ali havia um chefe viking enterrado; se o monte fosse violado, a ilha pegaria fogo. Essa história impressionou o menino, que buscava, cada vez mais, elementos para entendê-la. A jovem Helga e seu pai, o velho que cuidava do farol, conversavam com Gestur sempre que solicitados: sobre a ilha, sobre a história e sobre a nova companheira do menino. O velho sempre advertia: "ela é uma Valquíria e valquírias são perigosas". As valquírias são, frequentemente, comparadas às amazonas - guerreiras que governam a si próprias. A menina mostrava a Gestur os segredos da vida: "Cuidado, nunca se sabe o que essas Valquírias podem aprontar", dizia o velho faroleiro. A menina leva-o ao galinheiro, solta o galo no meio das galinhas e estabelece-se o seguinte diálogo:

Menina: O galo botará ovo em cima da galinha.

Menino: Ele põe o ovo na galinha?

- Sim, colocando o negócio nela.

- Mas o ovo sai da galinha.

- É como no homem; põe o negócio na mulher e nasce um bebê. Já viu a xoxota de uma menina? Eu te mostro se me der o seu emblema. Tem coragem de mostrar o seu pinto? Vi quando fazia xixi, é deste tamaninho.

Segredos, descobertas, embates... não pararam por aí. A menina convidou Gestur para subir no teto do celeiro para espionar os namorados:

- Estão praticando para quando casarem.

- É nojento.

- O que houve? É só o começo, nem chegou a parte boa! Agora sim, você viu uma xoxota! Viu ou não?

- Ela não gostava.

- Puxa! Santo Deus! Não é que ela não gosta. Ela sente cócegas. Depois fica com mais cócegas ainda!

A menina imita Helga sentindo um orgasmo: "Mais, mais... não pare! Não pare! É tão bom! Estou morrendo... Não pare... como é bom! É tão bom! Mais... Mais...".

\footnotetext{
"Ficha técnica: Hrafn Gunnlaugsson (direção) e Helgi Skúlason e Edda Bjorgvinsdóttir (atores). Gestur é um menino de sete anos acostumado com a tecnologia das grandes cidades: videogames e super-heróis da televisão povoam o seu universo. Certo dia sua mãe decide fazer uma viagem para o exterior e Gestur tem que trocar a cidade por uma bucólica ilha, onde o ritmo de vida é completamente diferente. Lá convive com uma garota de 20 anos de idade chamada Helga, seu pai, o velho faroleiro, seu namorado e uma menina da idade de Gestur. Entra também em contato com a história de um chefe viking enterrado na ilha.
} 
Toda essa avalanche de informações, entretecidas pelas histórias e emoções desencadeadas na ilha, pelas saudades e pelos ciúmes da mãe, que viajava com seu companheiro, suscitava sonhos e desenhos que povoavam a vida do menino.

O mar, que levava e trazia as pessoas à ilha, trazia também o namorado de Helga: fonte de competição para o menino desde que o viu pela primeira vez na parada do ônibus que o levava em direção ao acesso à ilha e ambos descem para fazer xixi: "Consegue mijar na pedra lá em cima? Não poderá fazer nada com as meninas se não conseguir".

Dias depois descobre que o moço era o namorado e ia casar-se com Helga: a mulher/moça que o colocava na cama para dormir, massageava-lhe os pés, convidava-o para ajudá-la nos afazeres diários e se banhava nua em sua companhia. O menino olhaa (que palavras poderia usar para dizer desse olhar!), ajuda-a a pegar o sabão, enxugaIhe as costas. Para a jovem Helga, a sua nudez era natural. Não havia vergonha, embaraço, mistério. Era um contato amoroso, tanto quanto os outros momentos que os dois viviam.

Gestur representava todas essas cenas através de desenhos. O namorado de Helga era representado por um monstro que deveria ser combatido e abatido.

Os sonhos eram frequentes e um deles resulta em polução noturna. Sonha com monstros e ele, um viking, salva Helga, que o abraça e o beija. Assustado vai ao banheiro trocar-se e o farol, ${ }^{12}$ nessa cena, controla tudo: ilumina e escurece as dúvidas, os anseios, os sentimentos conturbados do menino.

O menino do filme The Sacred Mound arquiteta violar o túmulo dos vikings com a cumplicidade da menina/Valquíria. Sua relação com ela, quase da mesma idade, era de competição, de troca de interesses, dos aprendizados nos segredos da vida. Quando resolve violar o túmulo, impelido pelo ciúme, no dia do casamento de Helga, ganha a admiração da menina, que se deita na cama a seu lado e beija-o na boca: o menino descobre quem é sua parceira para os jogos da sexualidade.

Mergulhando nas possibilidades de uma escrita rizomática, puxo o fio das expressões da sexualidade das crianças nos contextos sociais, históricos, culturais em que vivem na atualidade e pergunto: como o poder se exerce tornando-se invisível? Que espaços meninos e meninas têm para suas descobertas nessa dinâmica interativa que encharca o filme The Sacred Mound? Onde estão os panópticos? Nas instituições de educação infantil? Nas casas? Nos jardins? Nos parques?

Ou... na realização da Gincana Cooperativa? Que tentou constituir-se em uma "invenção", uma traição à mesmice, mas que - ao mesmo tempo - pode ter exercido muito controle sobre as crianças! Mas que - ao mesmo tempo - pode ter possibilitado descobertas!

Termino com Michel Foucault ${ }^{13}$ quando escreve: "Existem momentos na vida onde a questão de saber se se pode pensar diferentemente do que se pensa, e perceber diferentemente do que se vê, é indispensável para se continuar a olhar ou a refletir". Por isso o desafio de construir outro cenário, para continuar a refletir, o Projeto Tecendo Gênero e Diversidade Sexual nos Currículos da Educação Infantil. Mas essa é uma outra história que fica para outra vez!

\footnotetext{
${ }^{12}$ Michel FOUCAULT, 1994a. "O farol traz a figura arquitetural do Panóptico de Bentham. O poder se exerce tornando-se invisível" (p. 177)

${ }^{13}$ FOUCAULT, 1994b, p. 13
} 


\section{Referências bibliográficas}

CHEVALIER, Jean; GHEERBRANT, Alain. Dicionário de símbolos. 12. ed. Colaboração de André Barbault et al.; coordenação de Carlos Sussekind; tradução de Vera da Costa e Silva et al. Rio de Janeiro: José Olympio, 1998.

FOUCAULT, Michel. Vigiar e punir. 7. ed. Petrópolis: Vozes, 1994a.

História da sexualidade Il: o uso dos prazeres. 7. ed. Tradução de Maria Thereza Albuquerque e J. A. G. Albuquerque. Rio de Janeiro: Graal, 1994b.

GODOY, Ana. A menor das ecologias. São Paulo: USP, 2008.

JABOR, Arnaldo. Coluna de Arnaldo Jabor. O Globo, Rio de Janeiro, 23 set. 1997.

LAROSSA, Jorge. "O enigma da infância". In: Pedagogia profana: danças, piruetas e mascaradas. Tradução de A. Veiga-Neto. Belo Horizonte: Autêntica, 1999. p. 183-198. LOURO, Guacira Lopes. O corpo educado: pedagogias da sexualidade. 2. ed. 3. reimp. Belo Horizonte: Autêntica, 2007.

PROJETO DIREITOS SEXUAIS. Disponível em: <www.ded.ufla.br/direitosexuais >. Acesso em: 20 fev. 2011

[Recebido em 15 de março de 2011 e aceito para publicação em 10 de maio de 2011]

Children, Gender and Sexuality: Reality and Fantasy Enable Problematizations Abstract: In the dinamicy of intertextuality, in rhizomatic writing, I have woven three films - The oyster and the wind, The breast and the moon, The Sacred Mound - that depict children's different personal experiences of the discovery of sexuality and of gender relations. This is part of a larger project entitled "Weaving gender and sexual diversity in a protection network", funded by Secad/ MEC in 2007. This text is part of the subproject "The rights of the child". Many children who are protagonists of this play have made it possible to write this script. The text argues that the adult often applies the violent power of his/her look onto the child's desire - which can dodge such power-building an escape. But it also acknowledges that the adult can, intentionally, enable a child to saturate him/herself in the subject of sexuality and gender.

Key Words: Gender; Sexuality; Childhood.

614 Estudos Feministas, Florianópolis, 19(2): 605-614, maio-agosto/2011 